CRYSTAL STRUCTURE OF $\mathrm{Bi}_{2} \mathrm{PbMnO}_{4}\left(\mathrm{PO}_{4}\right)_{2}$, A NEW SOLID

SOLUTION SERIES IN THE Bi-Pb-Mn-P OXIDE SYSTEM H. Steinfink ${ }^{1}$ M. Huve ${ }^{2}$ P. Roussel ${ }^{2}$ O. Perez ${ }^{3 \text { he }}$

University of Texas Department of Chemical Engineering AUSTIN TEXAS 78712 USA

${ }^{1}$ Texas Materials Institute, University of Texas at Austin, Austin Texas 7871 ${ }^{2}$ Laboratoire de Cristallochimie et Phsicochimie du Solide, UMR CNRS 8012, ENSCL,BP 108, 59652 Villeneuve dAscq, France ${ }^{3}$ Laboratoire CRISMATISMRa, UMR CNRS 6508, 14050 Caen, France

The title compound is tetragonal, $P-42{ }_{1} c, \mathrm{a}=13.275(3) \AA, \mathrm{c}=5.500(2) \AA, \mathrm{Z}=$ 4. The structure refinement converged to $\mathrm{R} 1=0.0442$. On the basis of the $\mathrm{X}$ ray diffraction refinement the formula is $\mathrm{Bi}_{2} \mathrm{PbMnP}_{2} \mathrm{O}_{12}$. The crystal is an inverse twin. Electron diffraction revealed that the $\mathrm{X}$-ray diffraction lattice parameters are from a subcell. The true unit cell is $2_{\mathrm{a}}, 2_{\mathrm{b}}, 3_{\mathrm{c}}$. Single-crystal electron diffraction data lead to an apparent wave vector $q=1 / 2 a+1 / 2 b+$ $1 / 3 \mathrm{c}$, compatible with the Bravais lattice $4 / m m m P(1 / 21 / 2 \gamma)$. However, this choice leads to forbidden reflections due to the presence of a $2_{1}$ axis. An assumption that the crystal consists of a modulated, twinned orthorhombic structure with space group $C c c 2$ based on the cell $(2 a)^{2},(2 b)^{2}$, c leads to a modulation vector $\mathrm{q}=\mathrm{a}+\gamma(\mathrm{c})$. The $(3+1)$ dimensional Bravais lattice becomes $m m m C(10 \gamma)$ and the super space group is $\operatorname{Ccc} 2(10 \gamma)$. The refinement of the single crystal $\mathrm{x}$-diffraction data based on Ccc2 consisting of two $90^{\circ}$ twin domains led, as expected, to the identical result as the refinement in $P-42{ }_{1} c$. The crystal structure was determined from the X-ray diffraction intensities based on the subcell and represents an averaged structure. The $\mathrm{PO}_{4}$ radical can be present in two orientations. $\mathrm{Pb}$ occupies only $1 / 2$ of the crystallographic $8 \mathrm{e}$ positions. The $\mathrm{Pb}$ atoms bond through oxygen atoms from $\mathrm{PO}_{4}$ to form a ring, creating channels parallel to c. Manganese and oxygen are present within the channels but the average structure prevents the determination of their location with certainty.

Keywords: HEAVY METAL TRANSITION METAL PHOSPHATES, SOLID SOLUTION, SUPER SPACE GROUP,

Acta Cryst. (2002). A58 (Supplement), C343

\section{CRYSTAL STRUCTURES OF NEW INDIUM PHOSPHATE} MATERIALS

Robert W. Broach ${ }^{1}$ Robert L. Bedard ${ }^{1}$ Lisa M. King ${ }^{1}$ Richard M. Kirchner ${ }^{2}$ ${ }^{1}$ Uop 25 E Algonquin Rd. DES PLAINES ILLINOIS 60017 USA

${ }^{2}$ Manhattan College, Chemistry Dept., Bronx, NY 10471 USA

Unique structures have been obtained for new indium phosphate materials prepared by hydrothermal synthesis employing various organic structure directing agents, techniques that yielded the well-developed series of $\mathrm{AlPO}_{4}$ and $\mathrm{GaPO}_{4}$ microporous framework materials. Different structural properties can be expected for open framework indium phosphates than for $\mathrm{Al}$ and $\mathrm{Ga}$ phosphates because the increase in atomic radii from $\mathrm{Al}$ to $\mathrm{Ga}$ and In tends to favor octahedral coordination for In. Whereas most tetrahedrally bonded cations share only oxygen atoms at a vertex, as in conventional zeolite molecular sieves, octahedral cations may share pairs of oxygen atoms at an edge, or even three oxygen atoms at a face, allowing a greater variety in tetrahedral/octahedral framework topologies. Five new indium phosphate materials (RIPS-4, 6, 8, 11, and 13) have complex crystal structures different from all known $\mathrm{Al}, \mathrm{Ga}$ or In phosphates. RIPS-4: (ethylenediammonium) $\mathrm{In}_{3} \mathrm{P}_{3} \mathrm{O}_{12}(\mathrm{OH})_{2} \sim, \mathrm{C} 2 / \mathrm{m}, a=18.662 \AA b=6.600 \AA c=12.573 \AA$ and $\beta=$ $120.92^{\circ}, 12 \times 12 \times 42 \mu \mathrm{m}^{3}$ single crystal, $\mathrm{R}_{1}=0.0460,2 \mathrm{D}$ pores, open framework. RIPS-6: $\left(\mathrm{NH}_{4}\right) \mathrm{InPO}_{4}(\mathrm{OH}) \times 0.25 \mathrm{H}_{2} \mathrm{O}, \mathrm{P} 2_{1} / \mathrm{n}, a=9.627 \AA b=10.415 \AA c=$ $10.172 \AA \beta=97.94^{\circ}, R_{1}=0.046,3 \mathrm{D}$ pores, open framework. RIPS-8: $\mathrm{In}_{5} \mathrm{P}_{4} \mathrm{O}_{16}$ $(\mathrm{OH})_{3}\left(\mathrm{OH}_{2}\right)_{2}(\mathrm{en})_{3}, \mathrm{Pba} 2, a=10.54 \AA \quad=13.74 \AA c=9.847 \AA, \mathrm{R}_{1}=0.0334,1 \mathrm{D}$ pores, interrupted framework. RIPS-11: $\left[\mathrm{C}_{4} \mathrm{H}_{8}\left(\mathrm{NH}_{3}\right)_{2}\right]\left[\mathrm{InPO}_{4}(\mathrm{OH})\right]_{2}, \mathrm{Pbcn}, a$ $=22.4163 \AA b=5.6328 \AA c=9.9471 \AA$, Rietveld $\mathrm{R}_{\mathrm{F}}=0.0349 \mathrm{R}_{\mathrm{P}}=0.0881$, anionic indiumhydroxyphosphate layers pillared by 1,4-diammoniumbutane cations. RIPS-13: $\mathrm{NH}_{4} \mathrm{InPO}_{4}(\mathrm{OH}), \mathrm{P}_{1}{ }_{2} 2, a=9.4360 \AA b=9.4360 \AA c=$ $11.1952 \AA, R_{1}=0.0223,2 \mathrm{D}$ pores, open framework.

Keywords: INDIUM PHOSPHATE, MICROPOROUS FRAMEWORKS, TETRAHEDRAL OCTAHEDRAL FRAMEWORKS
Acta Cryst. (2002). A58 (Supplement), C343

THE EFFECT OF SULPHUR SUBSTITUTED PARTIALLY FOR SELENIUM ON THE STRUCTURAL AND MICROSTRUCTURAL PROPERTIES OF $S-\mathrm{Se}_{\mathrm{x}}$ SYSTEM

K. El Sayed Z.K. Heiba M.B. EL-Den

Faculty of Science, Ain Shams University. Physics P.O.Box 8014 Masaken Nasser City CAIRO 11371 EGYPT

Four samples $\mathrm{Se}, \mathrm{SSe}_{40}, \mathrm{SSe}_{30}$ and $\mathrm{SSe}_{20}$ were prepared as bulk in the amorphous phase and then to the polycrystalline phase by annealing at $373 \mathrm{~K}$ for 5, 20, and 120 minutes. The trend of the amorphous and polycrystalline diffraction patterns was similar, which indicates that the basic structural units in both states are also similar. The results showed that the changes in the structural parameters for samples $\mathrm{SSe}_{40}$ and $\mathrm{SSe}_{30}$ are different from that of sample $\mathrm{SSe}_{20}$ these discrepancies are being discussed in terms of: the peak shifts in both the amorphous and crystalline state, the percentage of sulfur compositional variations, stress and crystallite size and finally in terms of the probable site occupancy of the sulfur atoms in the selenium structure. 1) From the results, we noticed that for the four samples the crystallite size is increased by the annealing time and the microstrain is decreased. 2) The crystallite size for $\mathrm{SSe}_{40}$ and $\mathrm{SSe}_{30}$ is always less than that of pure selenium. 3) In case of $\mathrm{SSe}_{20}$ the situation is different. 4) The discrepancies in these findings were due to the site occupancy of sulfur atom in the structural units of selenium.

\section{Keywords: MICROSTRUCTURE, AMORPHOUS, POLYCRYSTALLINE}

\section{Acta Cryst. (2002). A58 (Supplement), C343 \\ X-RAY POWDER STRUCTURE OF A NOVEL LAYERED TIN(IV) PHOSPHATE, $\mathrm{Sn}\left(\mathrm{HPO}_{4}\right)_{2} \cdot\left(\mathrm{NH}_{3}\right)_{0.4}\left(\mathrm{H}_{2} \mathrm{O}\right)_{0.6}$

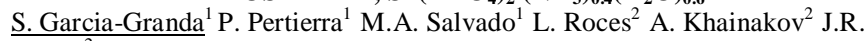 Garcia $^{2}$ \\ ${ }^{1}$ Dept. Physical \& Analytical Chemistry Facultad de Quimica, Universidad Oviedo Dept. Quimica Fisica y Analitica Av./Julian Claveria 8 OVIEDO, ASTURIAS ASTURIAS E-33006 SPAIN ${ }^{2}$ Departamento De Quimica Organica E Inorganica, Universidad De Oviedo, 33006, Oviedo, Spain.}

A novel layered tin(IV) phosphate, $\mathrm{Sn}\left(\mathrm{HPO}_{4}\right) \cdot\left(\mathrm{NH}_{3}\right) \cdot\left(\mathrm{H}_{2} \mathrm{O}\right)_{0.6}$, is synthesized under mild hydrothermal conditions. The crystal structure is solved for powder $\mathrm{X}$-ray diffraction data. The unit cell is trigonal, $\mathrm{a}=4$.9751(2) $\AA, \mathrm{c}=22.5983$ (8) $\AA$, space group $R-3, \mathrm{Z}=3$. The interlayer water and ammonia molecules are located in a disordered way in the same crystallographic site. This compound is the first example of a not monoclinic phase stable at room temperature in the well known family of $\alpha$-metal(IV) phosphates. Most of the $\alpha$ compounds are isostructural with $\alpha-\mathrm{Zr}\left(\mathrm{HPO}_{4}\right)_{2} \cdot \mathrm{H}_{2} \mathrm{O}$ and possesses a $P 2_{1} / \mathrm{c}$ monoclinic structure although the cell is pseudo $\mathrm{C}$-centered and pseudo hexagonal. In fact, two $\alpha$ phases are known that crystallize in the space group $C 2 / c$ and one high temperature phase in $R-3 m$. These diverse space groups can be related in a maximal group-subgroup chain where the $R-3 m$ can be considered as the parent structure of the $\alpha$-phases. In $\mathrm{Sn}\left(\mathrm{HPO}_{4}\right)_{2} \cdot\left(\mathrm{NH}_{3}\right)_{0.4}\left(\mathrm{H}_{2} \mathrm{O}\right)_{0.6}$, the water and ammonia molecules are located in a disordered way in the same crystallographic site, exactly at the center of four $\mathrm{OH}$ groups belonging to adjacent layers. A total of six symmetry equivalent intermolecular contacts are formed with $\mathrm{O} 1$ atoms. The short HO...OW (N) distance, 2.940(2) A, suggest the formation of interlayer hydrogen bonds. In the $\alpha$-tin(IV) phosphates, the $C_{2} / \mathrm{c} \quad$ symmetry of $\alpha-\mathrm{Sn}\left(\mathrm{HPO}_{4}\right)_{2} \cdot \mathrm{H}_{2} \mathrm{O}$ transform to $R-3$ for $\mathrm{Sn}\left(\mathrm{HPO}_{4}\right)_{2} \cdot\left(\mathrm{NH}_{3}\right)_{0.4}\left(\mathrm{H}_{2} \mathrm{O}\right)_{0.6}$, and the interlayer distance decreases from 7.81 to $7.53 \AA$. This contraction and the favorable hydrogen-bonding situation which results allow the half-exchanged $\gamma$-phase to form even in highly acid solutions.

Keywords: TIN(IV) PHOSPHATE LAYERED STRUCTURE 